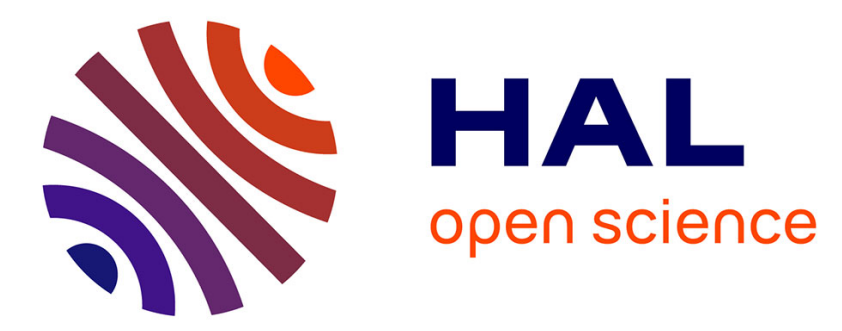

\title{
Assessment of cracks detection in pavement by a distributed fiber optic sensing technology
}

Xavier Chapeleau, Juliette Blanc, Pierre Hornych, Jean-Luc Gautier, Jean Carroget

\section{- To cite this version:}

Xavier Chapeleau, Juliette Blanc, Pierre Hornych, Jean-Luc Gautier, Jean Carroget. Assessment of cracks detection in pavement by a distributed fiber optic sensing technology. Journal of Civil Structural Health Monitoring, 2017, 7 (4), pp.459-470. 10.1007/s13349-017-0236-5 . hal-01582525

\section{HAL Id: hal-01582525 \\ https://hal.inria.fr/hal-01582525}

Submitted on 6 Sep 2017

HAL is a multi-disciplinary open access archive for the deposit and dissemination of scientific research documents, whether they are published or not. The documents may come from teaching and research institutions in France or abroad, or from public or private research centers.
L'archive ouverte pluridisciplinaire HAL, est destinée au dépôt et à la diffusion de documents scientifiques de niveau recherche, publiés ou non, émanant des établissements d'enseignement et de recherche français ou étrangers, des laboratoires publics ou privés. 
Noname manuscript No.

(will be inserted by the editor)

\title{
Assessment of cracks detection in pavement by a distributed fiber optic sensing technology
}

\author{
X. Chapeleau • J. Blanc · P. Hornych • \\ J-L. Gautier · J. Carroget
}

Received: date / Accepted: date

\begin{abstract}
This paper presents the feasibility of damage detection in asphalt pavements by embedded fiber optics as a new non-destructive inspection technique. The distributed fiber optic sensing technology based on the Rayleigh scattering was used in this study. The main advantage of this technique is that it allows to measure strains over a long length of fiber optic with a high spatial resolution, less than $1 \mathrm{~cm}$. By comparing strain profiles measured at different times, an attempt was made to link strain changes with the appearance of damage (cracking) in the pavement. This non-destructive method was evaluated on accelerated pavement testing facility, in a bituminous pavement. In our experimentation, the optical fibers were placed near the bottom of the asphalt layer. The application of 728000 heavy vehicle loads ( $65 \mathrm{kN}$ dual wheel loads) was simulated in the experiment. Optical fiber measurements were made at regular intervals and surface cracking of the pavement was surveyed. After some traffic, a significant increase of strains was detected by the optical fibers at different points in the pavement structure, before any damage was visible. Later, cracking developed in the zones where the strain profiles were modified,
\end{abstract}

IFSTTAR, COSYS, SII / Inria, I4S

Route de la Bouaye, 44340 Bouguenais, France

E-mail: xavier.chapeleau@ifsttar.fr

IFSTTAR, MAST, LAMES

Route de Bouaye, 44340 Bouguenais, France

E-mail: juliette.blanc@ifsttar.fr

IFSTTAR, MAST, LAMES

Route de Bouaye, 44340 Bouguenais, France

E-mail: pierre.hornych@ifsttar.fr

COLAS

Campus Scientifique et Technique, 4 rue Jean Mermoz, 78772 Magny les Hameaux, France

COLAS

Campus Scientifique et Technique, 4 rue Jean Mermoz, 78772 Magny les Hameaux, France 
thus indicating a clear relationship between the increased strains and crack initiation. These first tests demonstrate that distributed fiber optic sensors based on Rayleigh scattering can be used to detect crack initiation and propagation in pavements, by monitoring strain profiles in the bituminous layers.

Keywords Distributed fiber optic sensor - Asphalt concrete pavement . Cracks $\cdot$ Non-destructive inspection

\section{Introduction}

Due to the constant increase of traffic, roads suffer from cracks, rutting and surface wear more frequently. In the same time, users expect roads that are more and more safe and reliable in the meaning of permanently open. With increasing budget constraints, road managers have the difficult task to maintain roads in good condition. Pavement management systems can help them to make decisions for the planning of maintenance operations. One essential component of these systems is pavement monitoring, which includes visual surface inspection, traffic and weather observations and measurements on the pavement. Usually, this monitoring is made by an operator from a moving vehicle, or using automated sensors mounted to a vehicle. For more accurate diagnostics, sensors can be embedded in the pavement. Since several past decades, a wide variety of sensors was developed to measure strain and stress distributions in pavement structures. The data obtained by different in-situ measurements (stress, strain, displacement etc) are essential for a better understanding of pavement behaviour and identification of the main failure mechanism which is complex to determine due to pavement variability, temperature sensitiveness and viscoelasticity of pavement materials. By combining these data with numerical models [1], [2] pavement damage can be predicted more reliably. Moreover, embedded sensors offer an additional advantage. They make it possible to detect damage earlier than visual inspection. Since it is less expensive to keep a road in good condition than to repair it once it has deteriorated, the early detection of damage by in-situ sensors allows road managers to optimize their maintenance plan and to save money.

Pavements are multilayer structures, consisting of layers of granular and bituminous materials. The sensors used for pavement instrumentation must be compatible with the heterogeneous nature, and mechanical properties of pavement materials. First, the sensors should be as small as possible so that they are not too intrusive in the bituminous layers. Secondly for strain measurements, stiffness of the sensors has to match that of the asphalt mixture in order to measure correctly the mechanical properties of the pavement. Moreover, the embedded sensors must withstand the stresses experienced during the pavement construction process (high temperature and compression). After that, if a long term monitoring is considered, the sensor should be resistant to corrosion and to thermo-mechanical fatigue conditions.

Differents kinds of sensors can be used to monitor pavements. They can be classified in two categories: electrical sensors and optical fiber sensors. Classi- 
cal electrical sensors used for pavement instrumentation include displacement sensors, used to measure vertical displacements, strain gages, used to measure horizontal strains in bound pavement layers, temperature probes, and pressure cells, used to mesure vertical stresses or pressures in unbound pavement layers. Typical examples of pavement instrumentation used on the IFSTTAR (The French institute of science and technology for transport, development and networks) accelerated pavement testing facility can be found in [3]. Contrary to electrical sensors, fiber optic sensors are technologies which are a little less mature but promising. In civil engineering structures, there is a growing interest in fiber optic sensors because they offer attractive benefits when compared with traditional sensors [4], [5]. Their main advantages are small size, electrically passive operation, electromagnetic immunity, flexibility, corrosion resistance, etc. Moreover, fiber optic sensors can be used to perform local or distributed measurements with precision in a wide range of strain and temperature. Several fiber optic sensor technologies have already been used for experimental investigation of pavement behavior [6], [7] and pavement monitoring [8], [9] with positive results. The most tested is certainly the fiber Bragg grating technology. A fiber Bragg grating is a small portion of an optical fiber several millimeters or centimeters long in which a diffraction grating is written by UV exposure. The optical property of this grating is to reflect a narrow optical band (around a center wavelength called Bragg wavelength) of the incident spectrum. Fiber Bragg gratings have the intrinsic quality to be very sensitive to thermal and mechanical stimuli. The Bragg wavelength is proportional to the temperature and/or strain variation. Since, this sensor is very brittle, it needs to be packaged. Many tests of packagings with steel [10], polymer [11], geotextile [12] and so on were reported in literature. It is worth to mention that optical fiber sensors based on Fabry-Perot interferometry technologies were also tested [13] successfully. Since fiber optic sensor technologies (Fiber Bragg grating and Fabry-Perot) allow to perform dynamic measurements at a sampling rate of at least of $0.5-1 \mathrm{kHz}$ (for the standard interrogators), they are investigated particularly for the development of traffic classification and weigh-in-motion systems [14], [15].

Fiber Bragg grating and Fabry-Perot technologies [16] deliver a strain measurement like an electrical strain gage. It is a local measurement. Despite their high sensitivity and accuracy, they are not suitable for detection of cracks or damage. Indeed, due to their relatively small dimensions compared to those of a pavement, a crack can be detected only if it propagates in the vicinity of the sensor. A much more promising technology for damage detection is distributed sensing technique because in one acquisition, a lot of measurement points can be obtained along a long length of fiber optic which can be placed longitudinally or transversely in the pavement. Two distributed fiber optic sensing techniques based on the Brillouin scattering and the Rayleigh scaterring are available [17]. These two phenomenons result from the interactions of the light with the optical medium (the core of optical fiber). Rayleigh scattering is characterized as a quasi-elastic scattering where the scattered photons maintain the same frequency as the incident light. This penomenon is due to impuri- 
ties or density fluctuations of the refractive index on a scale smaller than the optical wavelength. Brillouin scattering is due to the interaction of the light with acoustic phonons. It is an inelastic phenomenon that lead to two spectral lines at Stokes and Anti-Stokes frequencies. These two distributed sensing techniques are sensitive to strain and temperature variations and the main difference between them is the spatial resolution. The Rayleigh scattering has the highest spatial resolution. Typically, it is $1 \mathrm{~cm}$ for Rayleigh and $0.5-1 \mathrm{~m}$ ( $25 \mathrm{~cm}$ for the best equipment) for Brillouin scatterings. This high spatial resolution of measurements is an asset for crack detection. Another parameter to take into account is the duration of measurement, less than 1 minute for the standard interrogators based on Rayleigh scattering and up to 10-15 minutes (depending of the length range and resolution chosen) for those based on Brillouin scattering. For both distributed sensing techniques and with standard interrogators, no dynamic measurements can be obtained. Nevertheless, it should be not a limitation for our study since cracking is a long term process of damage.

The study presented in this paper aims at assessing the use of the distributed fiber optic sensing technology based on Rayleigh scattering combined with the use of embedded fiber optics in pavements for early detection and localization of cracks. To be as close as possible to real conditions of pavement construction and traffic, this study was realized on a full scale demonstrator (circular pavement) and tested with the IFSTTAR accelerated pavement testing facility. The implementation of the fiber optics in the pavement layers represented a real challenge, due to high temperature and stress levels applied during construction.

The first part of the paper presents the accelerated pavement testing facility and the implementation of the distributed sensing technology based on Rayleigh scattering which is used for cracks detection. Then, the pavement structures and the experimental program are described. A total of 728000 load cycles have been applied in the experiment, until a significant level of damage of the pavements was attained. In the last part of the paper, results of the monitoring of the pavements with the fiber optic sensors are presented and discussed.

\section{Description of the test and measurement facilities}

\subsection{Accelerated pavement testing facility}

The IFSTTAR accelerated pavement testing facility (Figure 1), in Nantes (France), is an outdoor circular carousel dedicated to full-scale pavement experiments, carried out with public and/or private partners. The carousel consists of a central tower and four arms (each $20 \mathrm{~m}$ long) equipped with wheels, running on a circular test track. The experimental circular pavement has a mean radius of $17.5 \mathrm{~m}$ and a width of $6 \mathrm{~m}$, and thus a total length of approximately $110 \mathrm{~m}$. The position of the loading modules can be adjusted for 


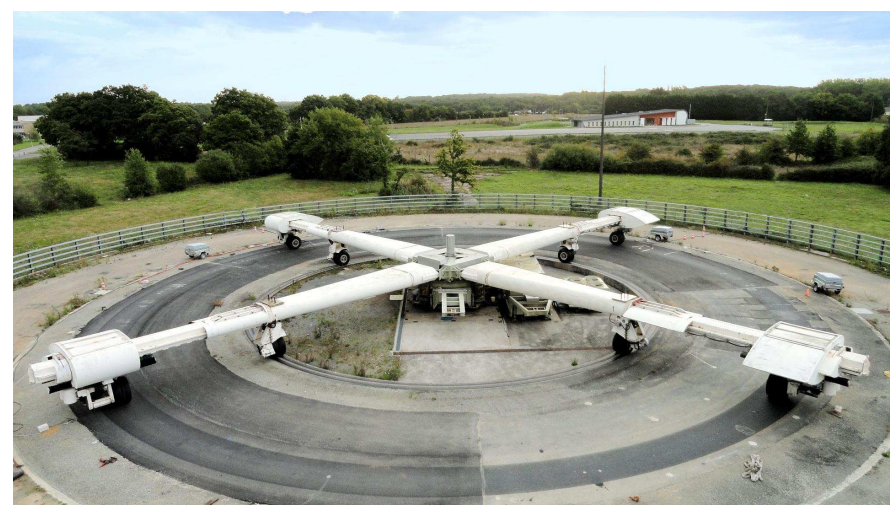

Fig. 1 Accelerated pavement testing facility of IFSTTAR.

different radii on each arm, for instance to test simultaneously the effect of different load configurations. During loading, a lateral wandering of the loads can be applied to simulate the lateral distribution of loads due to real traffic [18], [19]. The maximum operating speed is $100 \mathrm{~km} / \mathrm{h}$, which allows to apply approximately 1 million loads per month.

2.2 Implementation of Rayleigh scattering in distributed fibre optic for crack detection

In our experimentation, the distributed fiber optic sensing technology based on Rayleigh scattering was used. This phenomenon is due to random fluctuations of the refractive index profile along the length of the fiber optic. More precisely, the Rayleigh scattering in fiber optic is based on measurement of the shifts in the local Rayleigh backscatter pattern which depends on strain and temperature. Two successive measurements of the Rayleigh signal are necessary to obtain a strain or temperature profile. The first is used as reference. The typical accuracy of this distributed sensing technology is better than $\pm 1{ }^{\circ} \mathrm{C}$ in temperature and $\pm 1 \mu \mathrm{m}$ in strain with a centimeter spatial resolution. This high spatial resolution of the strain profile measurements is one of the main advantages of the distributed fiber optic sensing technology based on Rayleigh scattering.

Common single-mode fiber optic can be used with interrogators based on Rayleigh scattering. However, this component is too brittle to be embedded without conditioning in an asphalt mixture. The use of fiber optic cables specially designed for sensing measurement is preferable. Among all the many cables on shelf, the main criterion of choice concerns the coating of the cable. It should provide enough mechanical resistance in shear and against crushing by aggregates to withstand the stresses experienced during the pavement construction process. Moreover, it should not be deteriorated by high asphalt laying temperatures between $150{ }^{\circ} \mathrm{C}$ and $200{ }^{\circ} \mathrm{C}$. These requirements could 
lead to choose a stiff and thick coating to prevent damage of the fiber optic cable during pavement construction. However, increasing the stiffness of the coating reduces the sensitivity of the fiber optic sensor to strain. Moreover, a stiff cable could affect the local strain distribution in the pavement layer. Finally, the chemical compatibility between the coating and the asphalt mixture also needs to be considered. A good bonding between the fiber optic cable and the host material is obviously necessary. So, the choice of a fiber optic cable for pavement instrumentation is a trade-off between the features mentioned previously, in addition to the price, which is often high for fiber optic cables specially designed for measurement applications.

For early detection and localization of cracks, high sensitivity and high spatial resolution are critical parameters. Conversely, high accuracy for strain measurement is not absolutely required from our point of view. So, in this experiment, it was decided to use a telecommunication fiber optic cable with a price per meter that is 3-5 times lower than that of fiber optic cables specially designed for measurement. This low-cost solution is more acceptable for road managers and it was already tested in our laboratory for the monitoring of concrete (ballastless) track structures for high speed railway [21]. The fiber optic cable used in the pavement experiment contains 4 fibers (only one fiber optic was used for measurement) protected by an epoxy overcoat and a hytrel@ jacket. Some preliminary experiments were conducted in the laboratory to evaluate its thermal and mechanical resistance and its chemical compatibility with asphalt mixtures. Several small slabs of asphalt material with an embedded fiber optic cable were made with positives results. The slabs were compacted using a rolling wheel compactor, to simulate real compaction. A good bonding was observed and the fiber optic cable appeared to be robust enough to withstand compressive stresses and high temperatures occuring during pavement construction. These observations were made after the accelerated test. Excavations were made with a saw for bituminous materials, around the optical fiber position. So, it was possible to observe the good bonding between the bituminous mixture and the optical fiber.

Concerning the measurement system, we used a commercial device called "Optical Backscatter Reflectometer" (OBR manufactured by Luna). Strain or temperature profiles can be obtained from two measurements of the Rayleigh signal. The measurement range is approximately $70 \mathrm{~m}$ with a measurement time less than $10 \mathrm{~s}$. So, this new technology is limited to static tests up to now. However, its high spatial resolution is a positive asset for detection and localization of cracks in pavements. It is worth to underline that this sensing technique has already been tested successfully for damage detection in composites laminates [20], for crack detection in concrete [21] and for structural tests of wind turbine blades [22]. 


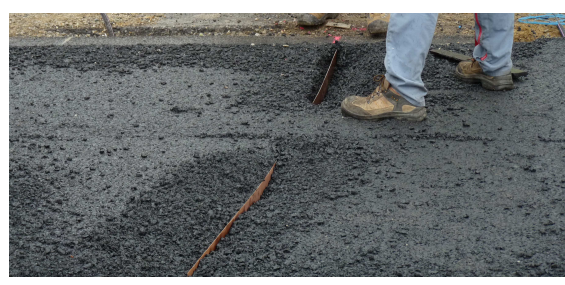

Fig. 2 Photographs showing the different types of steel bars embedded in the asphalt.

\section{Protocol of the experimentation}

3.1 Tested pavement structure and applied loads during the fatigue test

To test the response of the fiber optic cable with pavements of different stiffness, 2 representative French low traffic pavements [23] were constructed. The pavement structures consist of $80 \mathrm{~mm}$ of high modulus asphalt mixture (HMAM) for the first structure, and $80 \mathrm{~mm}$ of dense-graded bituminous mixture (DGBM) for the second, over a granular subbase (300 mm thick, $300 \mathrm{MPa}$ of modulus), and a sandy subgrade soil with a bearing capacity of about $95 \mathrm{MPa}$. DGBM is a standard French bituminous mix, with an elastic modulus at $15{ }^{\circ} \mathrm{C}$ and $10 \mathrm{~Hz}$ varying between 7000 and $9000 \mathrm{MPa}$ and a grade $35 / 50$ bitumen. This bituminous mix is specified in France for low traffic pavements. HMAM is a high modulus bituminous mix, with an elastic modulus at $15^{\circ} \mathrm{C}$ and $10 \mathrm{~Hz}$ varying between 12000 and $13000 \mathrm{MPa}$ and a grade $10 / 20$ bitumen. Usually, HMAM is used for base course, and is covered with a wearing course, but on the test track, it was decided to test it without wearing course to allow direct comparison with the other pavement. The conditions of construction of the pavement fatigue carousel were close to road or highway construction, at the difference that the compaction was slightly reduced in comparison with normal construction.

To accelerate damage (crack initiation in the pavement), steel bars with different shapes (triangular, $\mathrm{T}$ shaped and flat) were placed in the layer of asphalt as shown on Figures 2. The triangular steel bars (4 cm high) and the T shaped steel bars ( $4 \mathrm{~cm}$ high) were placed on top of the unbound granular material. The flat steel bars were put in the asphalt layer after the overlay and before the compaction. The asphalt was taken away with a trowel and the flat steel bars were pushed in with a hammer. All the steel bars were placed transversely to the wheel path axis as shown on figures 3 and 4 . The distance between two identical shape steel bars is approximately $40 \mathrm{~cm}$. It was expected that a crack would initiate at an early stage and propagate transversely to the wheel path axis between the two steel bars of the same shape.

In the experimentation, the four arms of the pavement fatigue carousel have been equipped with standard dual wheels, loaded at $65 \mathrm{kN}$ (standard French equivalent axle load). The tires used are Dunlop 1200 R20 SP321, inflated at $850 \mathrm{kPa}$ and the loading speed was 6 rounds per minute $(43 \mathrm{~km} / \mathrm{h})$. At the 


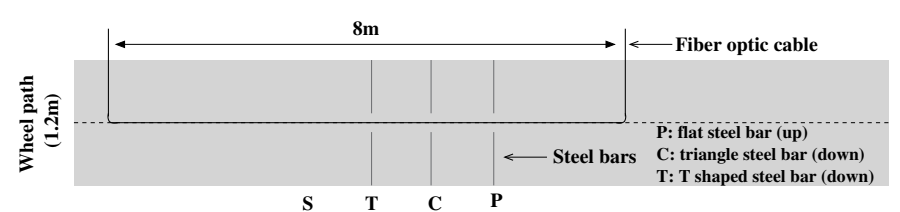

Fig. 3 Plan of implementaion of the fiber optic cable and of the steel bars in the pavement structure (top view).

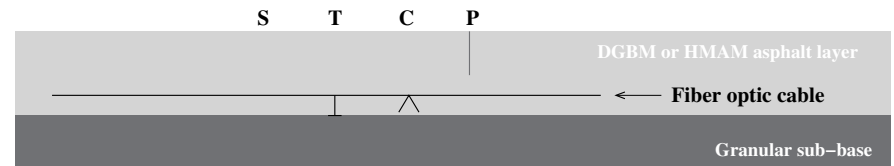

Fig. 4 Plan of implementaion of the fiber optic cable and of the steel bars in the pavement structure (side view).

beginning of the experimentation (until 308000 load cycles) the dual wheels were loaded at $65 \mathrm{kN}$. Afterward, the loads on each arm were increased to $75 \mathrm{kN}$, to accelerate pavement damage.

\subsection{Embedment of the fiber optic cable in the pavement}

As shown on Figures 3 and 4, the fiber optic cable was placed manually in the wheel path axis of the pavement over a length of $8 \mathrm{~m}$. In this configuration, it was expected that cracks initiated by the steel bars would intersect the optical cable perpendicularly. The integration of the optical cable in the asphalt layer was performed in three steps. First, a thin layer of asphalt (about $10 \mathrm{~mm}$ thick) was placed manually on the UGM foundation and compacted. Then, the optical cable was put on this layer of asphalt and it was covered manually by a thin layer of asphalt to maintain it in place. Finally, a paver and compactor were used to place an asphalt layer of $80 \mathrm{~mm}$. By this process, the optical cable was integrated in the pavement at $70 \mathrm{~mm}$ depth, near the bottom of the asphalt layer.

For the 2 sections (structures DGBM and HMAM), the fiber optic cable was embedded successfully in the asphalt layer without any damage. The fiber optic cable has withstood the high temperature of the asphalt mix (about $170{ }^{\circ} \mathrm{C}$ ) and the compaction of the pavement layer. Nevertheless, we recognize that the level of compaction was slightly reduced to avoid any risk of damaging irremediably the fiber optic cable.

\subsection{Protocol of fiber optic measurements}

For testing schedule reasons and maintenance operations of the pavement fatigue carousel, the experimentation was conducted in several phases: 
- between August 2012 and September 2012, until 308000 load cycles, with dual wheels loaded at $65 \mathrm{kN}$

- between December 2012 and January 2013, until 525000 load cycles, with dual wheels loaded at $75 \mathrm{kN}$

- between September 2013 and October 2013, until 675000 load cycles, with dual wheels loaded at $75 \mathrm{kN}$

- between October 2013 and December 2013, until 728000 load cycles, with dual wheels loaded at $65 \mathrm{kN}$

The fiber optic measurements were performed every 50000 load cycles and surface cracking of the pavement was surveyed at the same time. All the measurements were obtained using the same protocol. First, a "reference" measurement of the Rayleigh signal was performed. No load was applied on the area of the fiber optic embedded in the pavement. Next, one of the four dual wheels $(65 \mathrm{kN}$ or $75 \mathrm{kN})$ of the pavement fatigue carousel was placed at different positions "P", "C", "T" and "S" (Figures 3 and 4) above the fiber optic sensor and a second Rayleigh signal measurement was made on the loaded pavement. To minimize the influence of the viscoelastic asphalt material behavior (leading to creep of the material under static load), the same time interval was always kept between the application of the load and the Rayleigh signal measurement (one minute). In addition, the measurements at the different positions were performed, for each sequence, in less than 20 minutes, to avoid temperature variations.

It is worth to remind that, with the test procedure, a distributed strain variation is obtained along the optical fiber from 2 Rayleigh signal measurements made at different times. Obviously, this relative measurement depends on the reference adopted. For our experiment, 2 post-treatment methodologies were assessed. The first method (method A) consists in comparing the measurements made at the same number of load cycles, under the application of a static wheel load, and with no load (reference measurement). Thus, the strain profile obtained by this method represent the relative strain change between the "loaded" and "unloaded" state. At the end of the experiment, all the strain profiles obtained at different load cycles were compared, to try to correlate strain profile changes and surface cracking observations. The second method (method B) requires only the Rayleigh signal measurements obtained with no load at different load cycles. They were compared with the "reference" measurement performed at the beginning of the experimentation (at zero load cycles). With this second method, the strain profiles represent the evolution of strains along the optical fiber throughout the duration of the experiment. At the end of the experiment, all the strain profiles corresponding to different load cycles were compared to detect the appearance of significant changes in successive strain profiles (appearance of peaks for instance) which could be due to cracks in the pavement. 
(a)

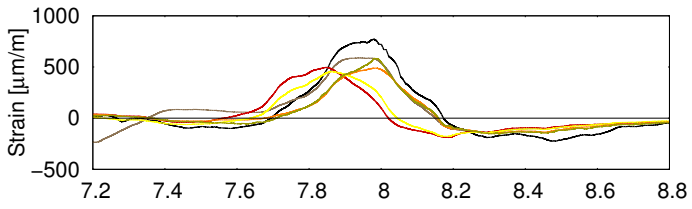

$\mathrm{N}=0$

$\mathrm{N}=100000$ $\mathrm{N}=150000$ $\mathrm{N}=200000$ $\mathrm{N}=300000$

(b)

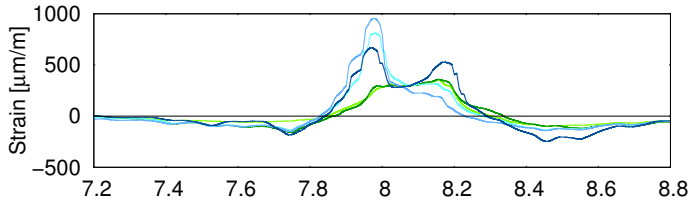

$\mathrm{N}=300000$ $\mathrm{N}=350000$ $\mathrm{N}=400000$ $\mathrm{N}=450000$ $\mathrm{N}=525000$

(c)

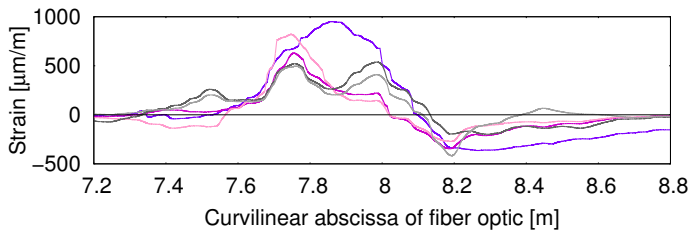

$\mathrm{N}=525000$ $\mathrm{N}=575000$ $\mathrm{N}=625000$ $\mathrm{N}=675000$ $\mathrm{N}=728000$

Fig. 5 Strains profiles obtained with loading at position "P" (structure HMAM).

\section{Results and discussion}

\subsection{Method A}

Figure 5 shows the strain profiles measured at different numbers of load cycles, with a static load applied at the position "P" (where the flat steel bars were placed to initiate cracking) for the structure HMAM (with high modulus asphalt mix). All the strain profiles from the beginning of the experimentation to 300000 load cycles have the same shape, which seems to indicate that no damage and no cracking occured during this period. Note that the peaks are slightly shifted in abscissa due to the fact that the tire (the load) was not placed exactly at the same position for the different measurements. Indeed, regular visual inspections did not permit to detect any cracks on the pavement until 350000 load cycles. The first cracks were detected on the surface of the pavement after 350000 load cycles. They appeared, as expected, at the ends of the steel bars placed in the pavement to initiate early cracks (Figures 3 and 4). At the same time, between 300000 and 350000 load cycles, the strain profile curves measured by the optical fibers started to change, the peak becoming wider and more flat in comparison with the previous measurements.

After 400000 and 450000 loads cycles, the maximum of the peak of the strain profile curves continued to increase and simultaneously, the surface crack propagated over the whole width of the pavement section. However, at the beginning, the crack remained very thin and difficult to detect by human eye. Then, at 525000 load cycles, the crack observed on the surface split in two cracks (Figures 6 and 7), and at the same-time, a second peak appeared on the strain profile. This result shows clearly the ability of the optic fiber to detect 


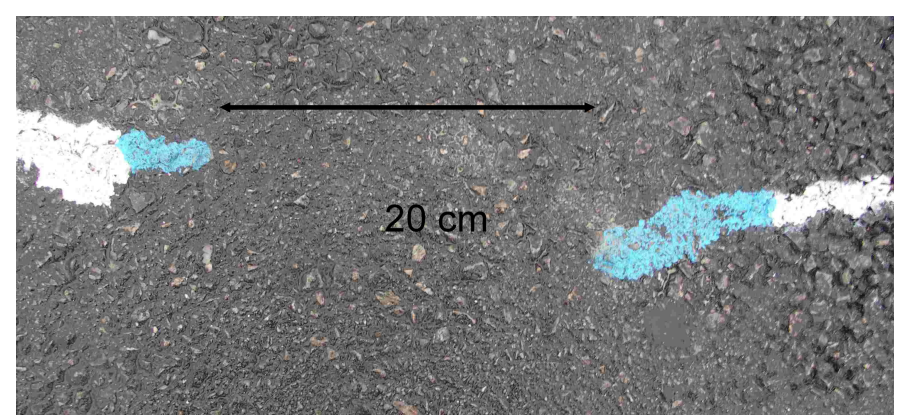

Fig. 6 Evolution of the first crack in the HMAM pavement structure localized at position "P" at 426000 load cylces.

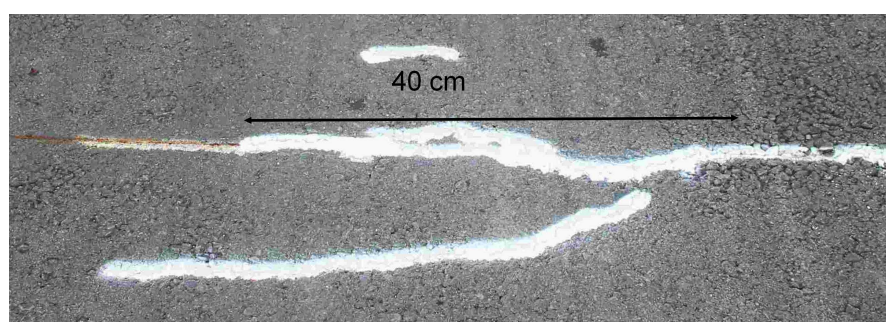

Fig. 7 Evolution of the first crack in the HMAM pavement structure localized at position "P" at 525000 load cylces.

the initiation of cracks in the pavement. It is probable that the two peaks on the strain profile can be distinguished because the distance separating the two cracks is sufficient (about $20 \mathrm{~cm}$ ). (The crack spatial resolution will be discussed later). Similar results were obtained at the positions "C" and "T", where steel bars were also inserted in the pavement. The evolution of strain profiles at these positions was very similar to that obtained at position "P". These measurements were again consistent with observations of cracks at the surface of the pavement. For position "S" where no crack was observed, the shape of the strain profiles remained similar during the test as shown on Figure 8. In conclusion, all these first results clearly demonstrate that distributed fiber optic sensors based on Rayleigh scattering can detect crack initiation by monitoring the shape of the strain profiles.

After this first test phase, the fatigue carousel was stopped during 8 months due to testing schedule reasons and maintenance operations (between January 2012 and mid-August 2013). Then, a new measurement was made after this rest period at 525000 load cycles. As shown on Figure 5, the two peaks in the strain profile has disappeared. This can probably be explained by a self healing of the bituminous material during the stop of the fatigue carousel. It is a known but not well understood phenomenon which can occur during hot periods and long rest periods. After 50000 new load cycles, the strain profile 

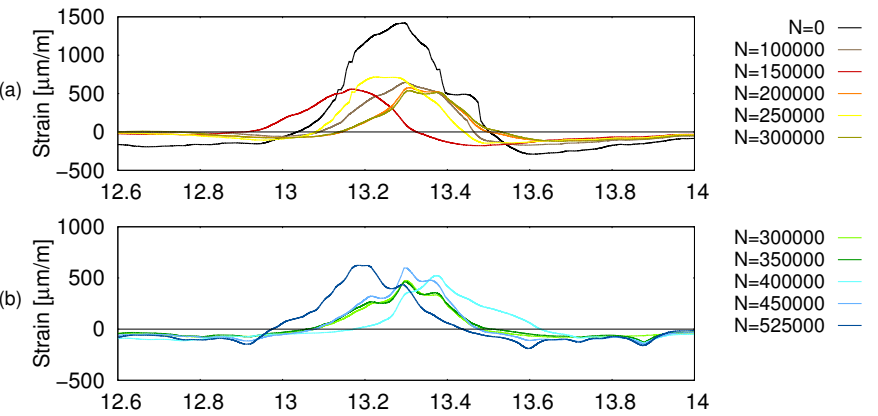

$\mathrm{N}=300000$
$\mathrm{~N}=350000$

$\mathrm{N}=350000$

$\mathrm{N}=450000$

$\mathrm{N}=525000$

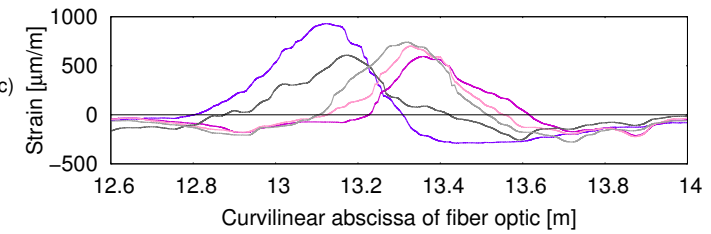

$\mathrm{N}=525000$

$\mathrm{N}=575000$

$\mathrm{N}=625000$

$\mathrm{N}=675000$
$\mathrm{~N}=728000$

Fig. 8 Strains profiles obtained with loading at position "S" (structure HMAM).

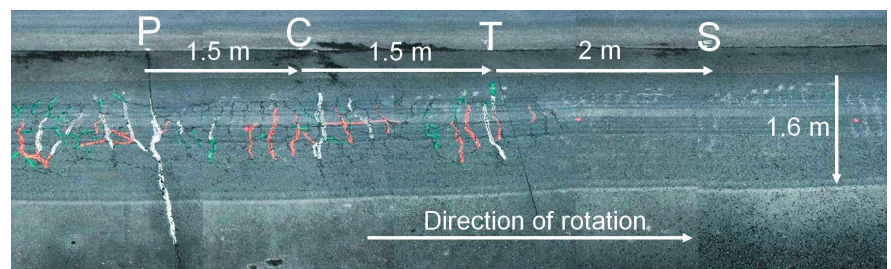

Fig. 9 Photograph of cracked pavement section HMAM at the end of the experimentation.

changed again, and at 728000 load cycles, the two peaks were again clearly visible on Figure 5.

At the end of the experimentation, a large part of the pavement HMAM structure between positions "P" and "T" was severely damaged (Figure 9). The cracks were interconnected, creating a pattern called "alligator cracking". It is worth to note that the fiber optic cable continued to respond well despite the severe cracking of the pavement structure. However, the multiple cracks could not be clearly distinguished, because the distance between them is less than the length of the stress transfer mechanism.

The second pavement structure consisted of an $8 \mathrm{~cm}$ thick layer of DGBM. This is a wearing course material, made with a softer bitumen grade $(35 / 50)$ than the high modulus asphalt material, and having a lower stiffness. This structure also presented some damage at the end of the experimentation, but the cracking was less severe, and the cracks were much finer than on the HMAM section (see Figure 10). On this second structure, the measurements made with the fiber optic cables indicated no significant evolution of the strain 


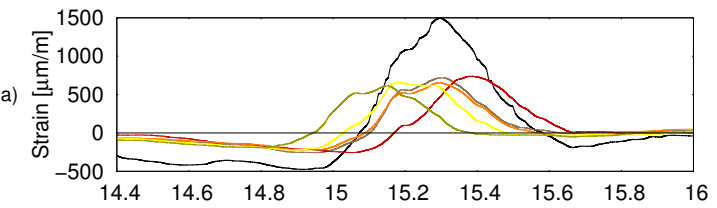

$\mathrm{N}=0$

$\mathrm{N}=100000$ $\mathrm{N}=150000$
$\mathrm{~N}=200000$ $\mathrm{N}=200000$ $\mathrm{N}=250000$
$\mathrm{~N}=300000$

(b)

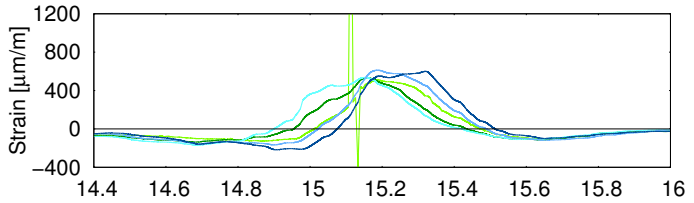

$\mathrm{N}=300000$

$\mathrm{N}=400000$

$\mathrm{N}=450000$

$\mathrm{N}=525000$

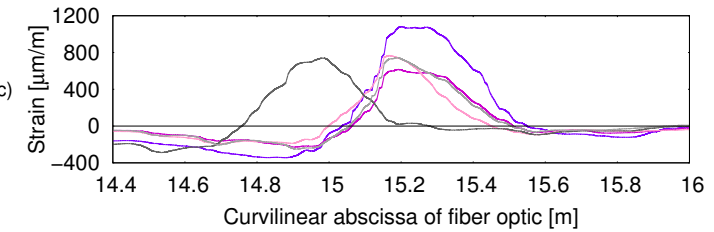

$\mathrm{N}=525000$

$\mathrm{N}=575000$

$\mathrm{N}=625000$

$\mathrm{N}=675000$

$\mathrm{N}=728000$

Fig. 10 Strains profiles obtained with loading at position "P" (structure DGBM).

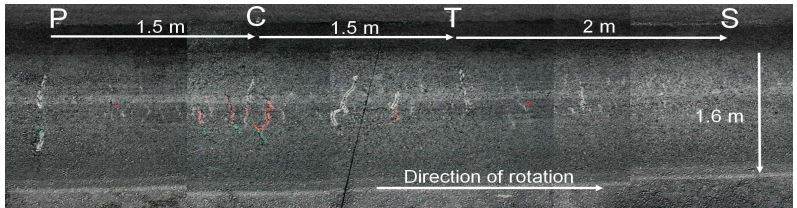

Fig. 11 Photograph of cracked pavement section DGBM at the end of the experimentation.

signals, all through the experiment. So, apparently, the fiber optic cables could not detect any significant cracking on that structure.

To try to explain this result, at the end of the experiment, several cores were taken from the HMAM and DGBM structures (Figures 12 and 13). Their observations confirmed that crack develoment was different on the 2 structures. Indeed, the cores of HMAM presented well visible, widely open cracks, affecting the whole height of the specimen, corresponding to classical "bottom-up" fatigue cracks [24]. On the cores of DGBM, on the contrary, the cracks were very thin, and were visible only in the upper part of the asphalt layer, indicating possibly a phenomenon of top-down cracking. This could explain why the fiber optic cable, placed at the bottom of the asphalt layer, has not detected these cracks.

\subsection{Method B}

In a perspective of monitoring of real roads, measurement method $\mathrm{A}$, which consists in measuring the optic fiber response under static load presents some practical difficulties : it is rather time consuming, because a static load must 


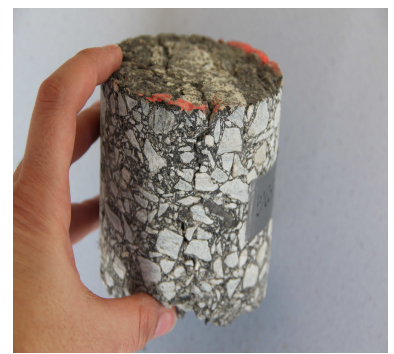

Fig. 12 Photograph of the cores taken from the HMAM structure.

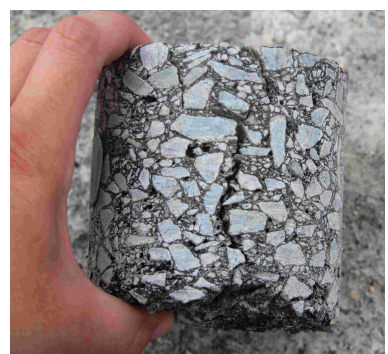

Fig. 13 Photograph of the cores taken from the DGBM structure.

be placed at different positions along the fiber optic cable, and because the lane must be closed to traffic during the measurements. Due to these limitations, a second monitoring method has also been tested. This method consists in making only one measurement, without any load, at different numbers $\mathrm{N}$ of load cycles, and in comparing this measurement at cycle $\mathrm{N}$ with a reference measurement, made at the start of the experiment, on the new pavement. This second method is more acceptable for road managers because it is faster and limits the disturbance of the traffic. However, with method B, the Rayleigh signal measurements were made at large time intervals (severals weeks or months), and thus at different seasons, and very different temperatures. For this reason, a temperature compensation appeared necessary to correct temperature dependence of the fiber optic cable response. To calibrate it, a small plate $(40 \mathrm{~cm} \times 20 \mathrm{~cm} \times 10 \mathrm{~cm})$ of HMAM containing a fiber optic cable was fabricated. This specimen was then placed in a thermal chamber and Rayleigh signal measurements were performed at temperatures from $5^{\circ} \mathrm{C}$ to $60^{\circ} \mathrm{C}$ by steps of $5^{\circ} \mathrm{C}$. Note that the measurements were made at interval of $24 \mathrm{~h}$ to ensure thermal stabilization of the specimen. From these measurements, strain profiles were calculated, taking the measurement at $20{ }^{\circ} \mathrm{C}$ as reference. Figure 14 shows the strain variations with temperature. Note that the ordinate of the graph is not real strain. The strain variations result from two effects. The first effect is the thermal expansion or contraction of the fiber optic sensor and surrounding material. The second effect is the dependence 


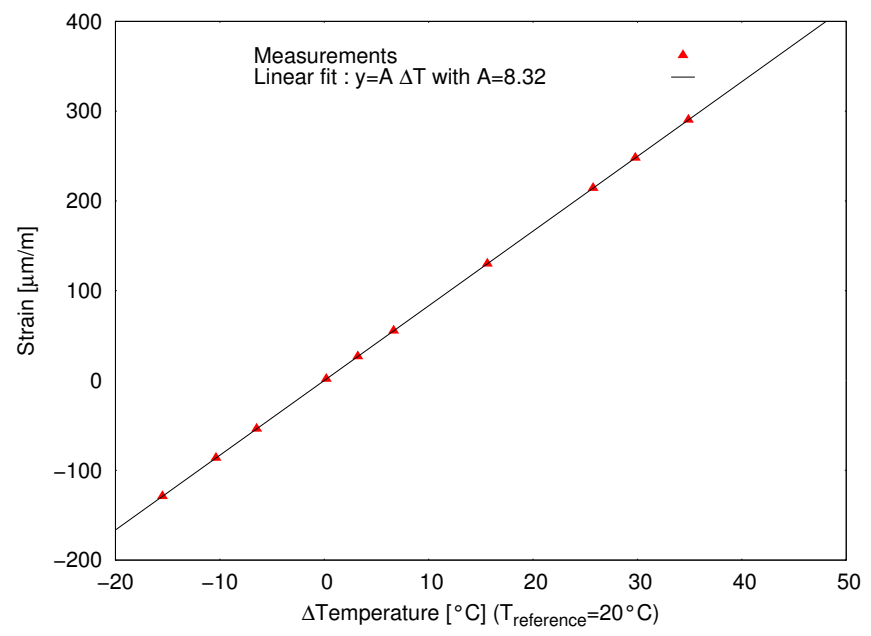

Fig. 14 Calibration of the fiber optic cable embedded in HMAM layer.

of the refractive index of the fiber optic with temperature, which shifts the Rayleigh backscattered pattern. This thermo-optic effect is generally the most important. The results on Figure 14 indicate a linear variation of strain with temperature. The mean slope of this curve is $8.32 \mu \mathrm{m} / \mathrm{m} /{ }^{\circ} \mathrm{C}$, and represents a correction factor which can be used to correct the measured strains.

Figures 15 and 16 present the strain profile curves obtained with method B for the HMAM and DGBM structures, respectively. They are compensated in temperature by using the calibration described above. At 100000 load cycles, the 2 figures show somewhat irregular strain profiles. These irregular variations are probably due to post-compaction of the asphalt layer caused by the applied wheel loads, at the beginning of the experiment. After this phase, no significant evolution of the strain profiles occurs between 100000 and 300000 load cycles, and a very good repeatability of the measurements can be observed. As described before, no cracks were detected on the 2 pavement structures by visual inspection and by fiber optic measurements (using method A) during this period.

For the HMAM structure, at 350000 load cycles, first significant changes can be observed on the strain profiles. The positions where these changes occur $(\mathrm{x}=8 \mathrm{~m}$ and $\mathrm{x}=9.5 \mathrm{~m})$ correspond well to the positions of the first cracks on the pavement, which were detected several thousand cycles later. At 400000 load cycles, two strain peaks appear at position " $\mathrm{P} "(\mathrm{x}=8 \mathrm{~m})$ corresponding to the two cracks observed close to this point (Figure 7). At 525000 load cycles, the entire strain profile located between $\mathrm{x}=7 \mathrm{~m}$ and $\mathrm{x}=12 \mathrm{~m}$ is strongly modified. This corresponds to the appearance and growth of various cracks in this area (Figure 9). For the portion of the fiber optic located between $\mathrm{x}=12 \mathrm{~m}$ and $\mathrm{x}=15 \mathrm{~m}$, however, the change of the strain profile curves is less significant. 

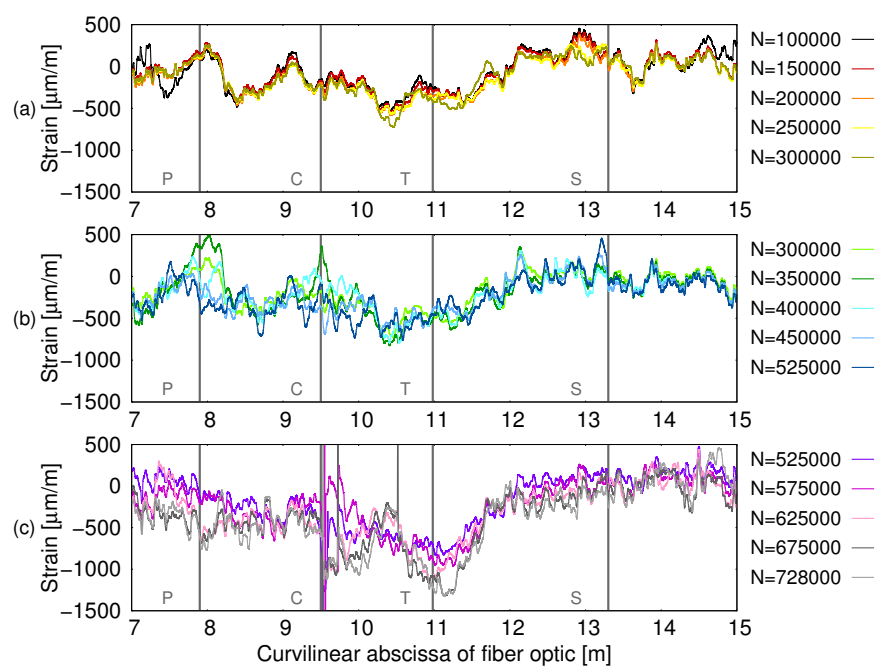

Fig. 15 Strains profiles obtained without loading (structure HMAM).

This is in accordance with the fact that no cracks were detected by visual inspection for $\mathrm{x}>12 \mathrm{~m}$, until the end of the experimentation.

For the DGBM structure (Figure 16), the results are different. The strain profiles remain very similar to that measured at 100000 load cycles up to the end of the experiment. These results are consistent with the observations made on this section, which indicated that cracking was less severe, and that the cracks were mostly superficial. This result is interesting, because it indicates that in the absence of significant cracks, which intercept the fiber optic cable, the strain profile measured by the fiber optic cable remains relatively stable.

The results obtained by method B for the HMAM structure are encouraging. The changes in the strain profiles measured during the lifetime of the pavement appear clearly related to the cracking of this structure. However, the information obtained is mainly qualitative, and it does not seem possible to identify precisely the number, length and opening of the cracks. Indeed, the strain transfer from the tested material to the core of the fiber depends on the structure of the optical cable, and its protective and adhesive layers [25], [26]. Each fiber optic cable has its own mechanical transfer function. For accurate crack opening measurements, it is essential to know this mechanical transfer function. However, its determination is not easy and requires to combine experimental results and numerical modelling. Often, the effective bond length is used as a parameter for characterizing the mechanical transfer function. This parameter corresponds to the shortest interfacial length necessary to transfer $97 \%$ of the applied load. For the fiber optic cable used in this experimentation, the effective bond length is about $25 \mathrm{~cm}$ [27]. This means that cracks which are close to each other (closer than the effective bond length) may not be spatially separated. The mechanical transfer function may also be affected 

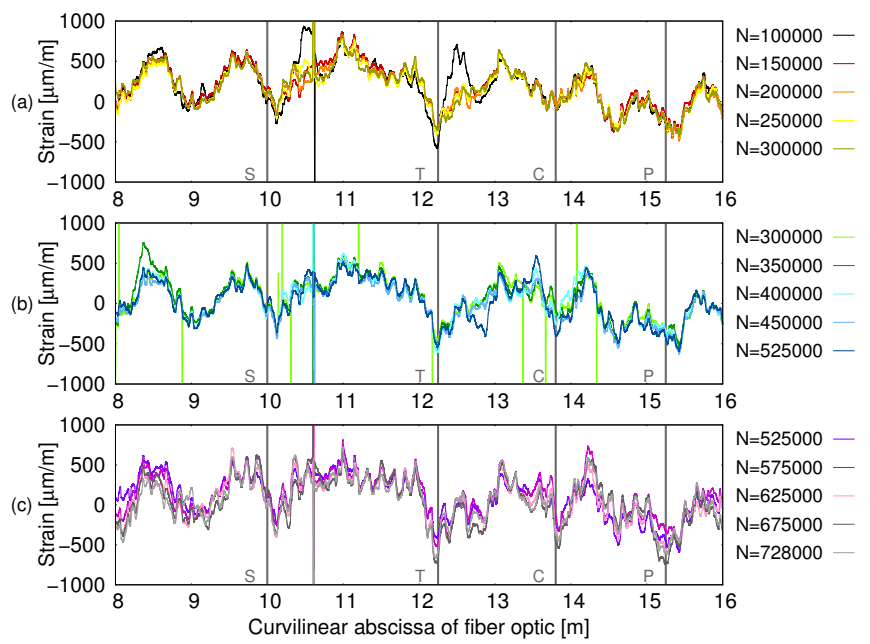

Fig. 16 Strains profiles obtained with loading (structure DGBM).

by several phenomena : debonding between the host material and the fiber optic, inelastic mechanical behaviour of the different elements (in particular the coating of the cable).

\section{Conclusion}

A new non-destructive technique for the detection of cracking in asphalt pavements was tested at real scale on the pavement fatigue carousel of IFSTTAR. It is based on the use of a fiber optic cable embedded in the pavement layer as distributed sensor. An optical interrogator based on the Rayleigh scattering was used to measure strain profiles. And from the evolution of the strain profiles measured at different times (after different levels of traffic) cracks can be detected. It is a first feasibility study of detection of cracks by embedded fiber optic sensors in asphalt layers and positive results were obtained.

Two different methods of post-treatment of the fiber optic measurements have been proposed. With both methods, significant changes of shape of the strain profiles could be directly linked to crack initiation and propagation. The method B which does not require to apply a load on the pavement is the most promising, since it is fast and allows to make measurements over relatively long distances of pavement, $70 \mathrm{~m}$ with the interrogator used in this study. Note that another technique called "Brillouin scattering" in distributed fiber optic could probably be used with similar results. Despite a lower spatial resolution (between $25 \mathrm{~cm}$ and $1 \mathrm{~m}$ ) than the Rayleigh scattering, the Brillouin scattering permits to scan longer lengths of optical fibers, up to several kilometers.

The choice of the fiber optic cable is critical for this type of application. First, it should withstand the harsh conditions of construction of the pave- 
ment. Secondly, it should have a good mechanical transfer function. In our experimentation, where a low-cost fiber optic cable was used, it was not possible to obtain quantitative information, such as number of cracks and crack width. Better results could probably be obtained with fiber optic cables specially designed for asphalt layers. Nevertheless, the study has demonstrated the possibility of early detection of cracks over long length of pavement using fiber optic cables interrogated regularly with interrogators based on the Rayleigh scattering, and this appears as a promising solution for road monitoring.

Further studies are planned to evaluate the efficiency of the technique described in this paper. The first results need to be confirmed for other pavement structures. Laboratory tests are also planned, to study the response of precracked asphalt beams, instrumented with optical fibers, using 4 point bending tests. These tests, carried out in controlled conditions, should allow to quantify precisely the sensitivity of the fiber to the presence of a crack in the asphalt, and the influence of various parameters (loading time, temperature, structure of the optical cable) on the results.

\section{References}

1. Chabot, A., et al.. Viscoroute 2.0: a tool for the simulation of moving load effects on asphalt pavement. RMPD Special Issue on Recent Advances in Numerical Simulation of Pavements, 11(2), 227-250, 2010.

2. Chupin, O., et al.. Evaluation of the Structure-induced Rolling Resistance (SRR) for pavements including viscoelastic material layers. Materials and Structures, 46(4), 683696, 2013.

3. Kerzrého, J.P., et al.. APT used for testing aggressiveness of different multi-axle loads on bituminous pavements. 4th International Conference on Accelerated Pavement Testing, Davis, California, USA. APT proceeding, 505-517, 2012.

4. Enckell, M., et al.. Evaluation of a large-scale bridge strain, temperature and crack monitoring with distributed fibre optic sensors. Journal of Civil Structural Health Monitoring, 1(1), 37-46, 2011.

5. Sigurdardottir, D. H., et al.. On-site validation of fiber-optic methods for structural health monitoring: Streicker Bridge. Journal of Civil Structural Health Monitoring, 5(4), 529-549, 2015.

6. Loizos, A., et al.. Fiber optic sensors for assessing strains in cold in-place recycled pavements. International Journal of Pavement Engineering, 14(2), 125-133, 2013.

7. Weng, X., et al.. Experimental investigation of pavement behavior after embankment widening using a fiber optic sensor network Structural Health Monitoring, Structural Health Monitoring, 14(1), 46-56, 2015.

8. Quintana, Juan A., et al.. SHM and evaluation of a continuous reinforced concrete pavement, Journal of Civil Structural Health Monitoring, 6(4), 681-689, 2016.

9. Nosenzo, G., et al.. Continuous monitoring of mining induced strain in a road pavement using fiber Bragg grating sensors, Photonic Sensors, 3(2), 144-158, 2013.

10. Fusiek, G., et al.. Metal-packaged Fiber Bragg Gratings for Structural Health Monitoring. Conference on Bragg Gratings, Photosensitivity, and Poling in Glass Waveguides, Barcelona, Spain, 2014.

11. Dreyer, U., et al., A technique to package Fiber Bragg Grating Sensors for Strain and Temperature Measurements. Journal of Microwaves, Optoelectronics and Electromagnetic Applications, 12, 638-646, 2013.

12. Artières, O., et al.. A fiber optics textile composite sensor for geotechnical applications, 4th European Workshop on Optical Fibre Sensors. Proceeding. SPIE, 7653, 1-4, 2010. 
13. Doré, G., et al.. Monitoring Pavement Response during Spring Thaw Using Fiber-Optic Sensors. 6th International Conference on the Bearing Capacity of Roads, Railways and Airfields, Lisbon, Portugal. Proceeding, 15-24, 2002.

14. Lydon, M., et al.. Improved axle detection for bridge weigh-in-motion systems using fiber optic sensors, Journal of Civil Structural Health Monitoring, 7(3),325-332, 2017.

15. Xue, W., et al.. A Review and Perspective about Pavement Monitoring, International Journal of Pavement Research and Technology, 5(5),289-294, 2012.

16. Grattan, K., et al.. Fiber optic sensor technology: an overview. Sensors and Actuators A: Physical, 82, 40-61, 2000.

17. Barrias, A., et al.. A Review of Distributed Optical Fiber Sensors for Civil Engineering Applications. Sensors, 16(5), 748, 2016.

18. Gramsammer, J.C., et al.. The LCPC's A.P.T. Facility: Evaluation of fifteen years of experimentation, 1st International Conference of Accelerated Pavement Testing, Reno, Nevada, USA, 1999

19. Nguyen, M.L., et al.. Review of glass fiber grid use for pavement reinforcement and APT experiments at IFSTTAR, Road Materials and Pavement Design, 14(1), Special Issue: EATA 2013, 287-308, 2013.

20. Güemes, A., et al.. Optical Fiber Distributed Sensing - Physical Principles and Applications, Structural Health Monitoring, 9, 233-245, 2010.

21. Chapeleau, X., et al.. Study of ballastless track structure monitoring by distributed optical fiber sensors on a real-scale mockup in laboratory. Engineering Structures, 56, 1751-1757, 2013.

22. Kaplan, A., et al.. Distributed optical fiber sensing for wind blade strain monitoring and defect detection. 8th International Workshop on Structural Health Monitoring, University of Stanford, Stanford, USA. IWSHM proceeding, 394-401, 2011.

23. Corte, J.F., et al.. M.T.6. Design of pavement structures : the French technical guide. Transportation Research Record, 1539, 116-124, 1996.

24. Hornych, P., et al.. The LCPC's ALT facility contribution to pavement cracking knowledge. In Pavement Cracking - Mechanisms, Modeling, Detection. Print ISBN: 978-0-41547575-4, chapter 2, 13-23, 2008.

25. Ansari, F., et al.. Mechanics of bond and interface shear transfer in optical fiber sensors. Journal of Engineering Mechanics, 124(4), 385-394, 1998.

26. Wang, H., et al.. Advances of strain transfer analysis of optical fibre sensors. Pacific Science Review, 16(1), 8-18, 2014.

27. Henault, J-M., et al.. Analysis of the strain transfer mechanism between a truly distributed optical fiber sensor and the surrounding medium. 3rd International Conference on Concrete Repair, Rehabilitation and Retrofitting. Cape Town, South Africa. ICCRRR 2012 Proceeding, 733-739, 2012. 